\title{
Stories Notebook about the Fundamental Concepts in Family Medicine: Continuity, The Fable of The River with Meanders
}

\author{
Jose Luis Turabian *
}

Health Center Santa Maria de Benquerencia Toledo, Spain

"Corresponding author: Jose Luis Turabian, Health Center Santa Maria de Benquerencia Toledo, Spain, Tel: 34925154508; Email: jturabianf@hotmail.com

Received date: January 10, 2017; Accepted date: January 25, 2017; Published date: February 02, 2017

Copyright: ( 2017 Turabian JL. This is an openaccess article distributed under the terms of the Creative Commons Attribution License, which permits unrestricted use, distribution, and reproduction in any medium, provided the original author and source are credited.

\section{Introduction}

In this section of "Stories Notebook About the Fundamental Concepts In Family Medicine" you will learn the fundamental concepts of General Medicine/Family Medicine through stories or fables.

Conceptual systematization in the specialty of Family Medicine/ General Medicine has not matched with practice. However, it is not until that the conceptual heritage of Family Medicine, is ordered, systematized and fully clarified when it can begin the real practical work. Therefore, it is necessary to achieve more meaningful representations of the fundamental concepts of Family Medicine, and facilitate the transfer of these to clinical practice. But, these concepts can be difficult to understand and explain, even for experienced physicians in the specialty [1-4]. Thus, we propose the following concepts of Family Medicine/General Medicine, which we think are the main:
1. Comprehensiveness and integrality
2. Continuity
3. Context and contextualization
4. Uncertainty
5. Complexity
6. Community
7. Patient centered Interview
8. Biopsicosocial Model

9. Actors and resources/strengths of the patients;

10. Medicalization and technology

11. Family

12. Symptoms

13. Diagnosis and treatment

14. Concept of health and disease

\section{Variability}

Evidence Based Medicine, clinical trials and quantitative studies are necessary, indispensable for medical science, yes, but why not the stories, the tales and the cases? So, we will be presented these concepts by fables.

The fable is an adult education method that can serve to intuitively understand abstract concepts by linking them to specific situations, for facilitating their assimilation. Animals, plants, minerals and other things will be "patients" seen in consultation by the family doctor $[5,6]$. They will be fictional stories presented as real. They will be beings or objects that are given the opportunity to think, feel and speak. In the fable it can be distinguished two parts: one is the story itself; and the other moral. Each story seeks to make emerge, of clear form, the moral, the end of the fable, as sobering consequence of what happened in the episode. The moral will be a fundamental concept of Family Medicine/General Medicine [7,8].

\section{Short Communication}

Long ago, Mr. River with Meanders consulted his family doctor. He was a river with many curves. Within it there were differences in flow velocity producing the excavation of its riverbed. The most decisive of this consequence was the formation of meanders. Thus, concavities and convexities occurred along one same edge. The concavity appeared because of the excavation produced by the inertia of the movement of the flow of river water on the curve. The convexity appeared on the opposite shore, where the water velocity is lower and therefore is where tend to accumulate the fragments. By hitting the water flow repeatedly one river bank, tends to grow this to the detriment of the other bank, forming the bend. But the meanders are dynamic forms that evolve over time (Figure 1).

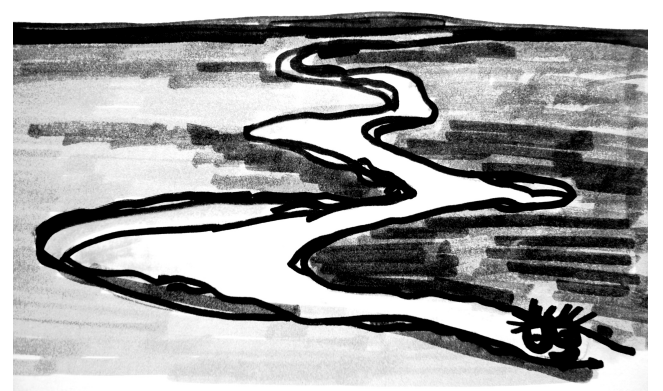

Figure 1: The Fable of The River With Meanders.

"I have another letdown, Doctor. Again I noticed I be sad, discouraged, wanting to mourn, as has happened to me other times, although three months ago I was well, so I let medication after taking it almost a year, do you remember, Doctor?".

"Yes, of course, I remembered, Mr. River with Meanders. Although earlier, similar outbreaks had already occurred, and you also took antidepressants", replies the doctor, as he reviewed his medical records. 
"And again with my aching guts, Doctor", said Mr. River with Meanders. "I think they are gas in the gut, and my chronic constipation. In addition, although I like all kinds of food, some foods I feel bad, by heaviness of guts or diarrhea. Although it may be by the water I drink".

The doctor looks at his medical history: he had been diagnosed of gallstones, which did not improve his clinic after cholecystectomy. And these symptoms are often repeated.

The doctor thought: "What is his diagnosis, recurrent depression, dysthymia, constipation, irritable bowel syndrome, and gallstones or had other psychosocial factors covering your entire clinic? How is this disease that appears and disappears"?

And the doctor knows that this is common effect in medicine:

"The depressions improve, but in this person reappear after years or months; and other symptoms appear and disappear: nonspecific abdominal pains, epicondylitis, painful shoulder, lower back pain. Where is this river? What valleys, what mountains, what woods are crossed by the river? What tributaries does this river have? How are the bridges that cross it? How is your delta at the mouth of the sea? What fauna and flora are there in the environment of this river? Is it a calm river, fast, mighty, short, long, navigable, perhaps? How is the color of its waters, blue, gray, green? It is simply that unfolds the life before our eyes, through our experience. Life is nothing but a river full of meanders: each of the curves describing the course of a river", the doctor told himself.

The doctor thought: "the continuity of care, perhaps over many years, is considered to be a defining characteristic of family medicine and an essential attribute of primary care. Continuity of care between the doctor and the patient builds trust and allows the physician to use more productively the time available. One priority object of medical studies should be the knowledge of the natural history of the disease. Ignorance of this evolution can lead to significant errors of judgment on the therapeutic indications. Knowing the evolutionary trend of the disease, the doctor can foresee success or failure. Knowledge of the repetition of a certain pattern of expression of a symptom in a patient, or variation in the expected pattern, gives us the diagnosis".

"The general practitioner not only involved in trying to move the person toward health, but also acts as a witness to the patient experience. He or she is someone prepared to observe what happens over time, to inform and even think about it; he or she is someone prepared to leave aside prejudices and assumptions, and to see what really happens, not just what biomedicine can expect to happen".

The continuity of care allows to the doctor to see repeated patterns of events and trends or regularities through generations, family functioning and its relationship to events, family structure, coalitions between members, the family rules, myths, rituals, etc.; It lets to the Doctor see patterns beneath the apparent diversity of reasons for consultation; It facilitates the diagnosis and treatment, monitoring of the chronically ill, the implementation of preventive elements, and improves patient satisfaction. The evolution in humans is not a linear process or progressive of accumulation, but a dialectical process in which the crises of life always impose us a while to back and another forward. Patients have to be considered in the context of their families and communities, and through the long doctor-patient relationships.

\section{References}

1. Wileman L, May C, Chew GCA (2002) Medically unexplained symptoms and the problem of power in the primary care consultation: a qualitative study. Fam Pract 19: 178-182.

2. Stewart M, Brown JB, Weston WW, McWhinney IR, McWilliam CL, et al. (1995) Patient centered medicine. Transforming the clinical method. London: SAGE Publications.

3. Turabian JL, Perez FB (2015) Observations, insights and anecdotes from the perspective of the physician, for a theory of the natural history of interpersonal continuity. The colors of time. Rev Clin Med Fam 8:2.

4. Turabián JL, Samarín OE, Minier L, Pérez FB (2015) Learning concepts of diagnosis in family medicine: the "mark robinson sign" - the traces that should not be there. Aten Primaria 47: 596-602.

5. Turabian JL, Perez FB (2010) The diagnostic concept in family medicine: A view of the landscape. Aten Primaria; 42: 666-669.

6. Turabian Jl, Perez FB (2010) An easy or difficult case? Shapes drawn from life. Uncertainty based family medicine. Semergen $36: 485-490$.

7. Mechanic D (2001) How should hamsters run? Some observations about sufficient patient time in primary care. BMJ 323: 266-268.

8. Turabián JL, Pérez FB (2016) Family physician's travel notebook. Meander. Rev Clin Med Fam 9: 221-223. 